\title{
FENOMENOLOGIA E FENÔMENO EM MAURICE MERLEAU-PONTY
}

\author{
PHENOMENOLOGY AND PHENOMENON IN MAURICE MERLEAU-PONTY
}

Paulo Pimenta Marques*

\section{Onde se situa a Fenomenologia da percepção?}

A obra Fenomenologia da Percepção, segundo livro de Merleau-Ponty, a mais conhecida e a mais estudada, compõe, juntamente com o primeiro livro, A Estrutura do Comportamento, um todo onde as duas obras se interligam e até mesmo se completam, do ponto de vista de uma filosofia do corpo. O problema do primeiro livro é compreender as relações entre a consciência e a natureza em todas as suas dimensões. Depois de debater com o objetivismo behaviorista e a psicologia da gestalt, o empirismo e o intelectualismo criticista, examinando a consciência perceptiva como uma solução para os impasses da relação do corpo e da alma, relação essa que traduz o tema geral que o ocupou, conforme ele mesmo diz, durante aproximadamente quinze anos de pesquisa, ${ }^{1}$ já ao final da obra, Merleau-Ponty faz surgir o problema do espectador que participa do espetáculo que ele mesmo percebe. A investigação deve então se dar agora não mais no plano das relações objetivas das ciências e da psicologia clássicas, dos dados da experimentação científica e da psiquiatria, mas em outro, o da experiência que nós mesmos vivemos, a experiência da percepção, do homem como ser-no-mundo. Todavia, se a solução apontada pelo criticismo implica em adotar uma “teoria intelectualista da percepção", então ela deve ser rejeitada, restando somente "redefinir a filosofia transcendental de maneira a nela integrar até o fenômeno do real", pondera

\footnotetext{
* Mestre em filosofia pela UFMG - E-mail: marx.paulo@gmail.com.

${ }^{1}$ Emmanuel de Saint Aubert, em seu livro de 2005, cita uma entrevista dada por Merleau-Ponty em 1959, onde o entrevistador pergunta qual o sentido, para Merleau-Ponty, das pesquisas em filosofia pura. Merleau-Ponty responde: "lembro-me muito bem que, ao final dos meus estudos, liguei-me às relações da alma e do corpo como a um problema que interessava-me especialmente. Continuei assim durante quinze anos, e foi o resultado desse esforço que apareceu sob a forma de dois livros (...) que são, todos os dois, dedicados mais ou menos ao problema das relações da alma e do corpo" (2005, p. 18, tradução nossa).
} 
Merleau-Ponty (Fenomenologia da percepção: PhP, p. 241, 255) ${ }^{2}$. Essa redefinição da filosofia transcendental que tem como objetivo compreender o sentido imediato da vida perceptiva, e de pensá-lo como tal, instalando-se nela, será a obra Fenomenologia da Percepção.

\section{Qual fenomenologia para Merleau-Ponty?}

A fenomenologia da percepção é, antes de toda interpretação científica, uma exploração do que subjaz à nossa experiência do mundo, e a percepção é o melhor caminho para acessarmos esta camada básica, sem omitir seus sentidos e ausência de sentido, suas claridades e ambiguidades. O que é a percepção ou a experiência perceptiva para MerleauPonty? A percepção se dá, ele afirma, não por uma operação intelectual, mas quando retomamos por nossa conta o modo de existência das coisas oferecidas a nós com nossa maneira de tratar o mundo (MERLEAU-PONTY, 1945, p. 369, 428).

Merleau-Ponty adota à sua maneira a fenomenologia de Husserl, cujos temas mais gerais são: o retorno às coisas mesmas, a descrição, a redução, a constituição e a intencionalidade. A redução fenomenológica - que é talvez o tema principal - deve fazer aparecer o mundo, o mundo da percepção, o mundo natural e social. Além de ser uma filosofia transcendental que coloca em suspenso, para compreendê-las, as afirmações da atitude natural, a fenomenologia de Merleau-Ponty é também uma filosofia que revela a presença inalienável do mundo por uma descrição direta de nossa experiência tal como ela é. Dessa forma, longe de ser a fórmula de uma filosofia idealista, "a redução fenomenológica é a fórmula de uma filosofia existencial: o 'In-der-Welt-Sein' de Heidegger só se manifesta sobre o fundo da redução fenomenológica” (MERLEAU-PONTY, 1945, p. IX, 11). A originalidade da fenomenologia transcendental de Merleau-Ponty reside no fato de que ele faz do ser-nomundo (In-der-Welt-Sein) de Heidegger o verdadeiro resultado da redução husserliana por ele modificada, tornada não idealista. O último Husserl, da época do Lebenswelt, do retorno ao mundo da vida, é mantido como a fonte principal.

\footnotetext{
${ }^{2}$ Indicamos, primeiro, a paginação original e depois a da tradução brasileira. Traduções não indicadas são de nossa autoria.
} 


\subsection{Algumas características da fenomenologia de Merleau-Ponty: a redução e a intencionalidade}

\subsubsection{Redução eidética e redução transcendental}

O que é a redução para Merleau-Ponty? Vejamos como Merleau-Ponty, conforme Kwant (1967), se contrapõe a Husserl quanto aos dois tipos de redução fenomenológica, primeiro à redução eidética, e em seguida à redução transcendental.

Husserl está convencido de que há uma essência humana. Essa essência humana, com seus vários aspectos, por exemplo, a consciência e a corporeidade, pode ser conhecida através da redução eidética, o que significa que a filosofia atingiria uma de suas metas se, através dessa redução eidética, ela puder penetrar no núcleo essencial do homem. Para MerleauPonty, ao contrário, não há essência humana. No homem, tudo está conectado, não há nada acidental. Todavia, esta conexão não é garantida por uma essência, mas por uma gestalt, o que não afasta o fato do homem estar permeado pela contingência, uma vez que consideramos sua historicidade e rejeitamos a ideia de um ser puramente de natureza. Tudo o que podemos fazer com a redução é compreender uma interconexão existencial, para a qual precisamos de fixações conceituais, sempre correndo o risco de vermos essas noções ameaçarem fixar a existência humana.

Quanto à redução transcendental, do último período de Husserl, Kwant destaca dois de seus aspectos: 1) colocar o ser entre parênteses, para buscar o conteúdo real do fenômeno; 2) tentar penetrar naquilo que é original na nossa vida intencional. Husserl não duvida da realidade. $\mathrm{O}$ que ele quer é analisar a estrutura do fenômeno, penetrar na natureza de nossos atos intencionais aos quais os fenômenos correspondem, já talvez delineando os traços de seu idealismo transcendental. Em Merleau-Ponty, ao contrário, não há traços de redução metódica de inspiração cartesiana. Não importa quão profundamente exploremos o sujeito, sempre encontramos o mundo. Para ele, por exemplo no capítulo sobre o cogito, "o interior e o exterior são inseparáveis. O mundo está inteiro dentro de mim e eu estou inteiro fora de mim." (MERLEAU-PONTY, 1945, p. 466-7, 546). Para Husserl, então, o sujeito transcendental é o sujeito pensante distinto do empírico vivendo no mundo concreto. Seria ele um sujeito espiritual? Para Merleau-Ponty, isso não passa de uma ilusão abstrata, onde o sujeito perdeu de vista suas raízes concretas. Quanto à busca do original em nossa vida 
intencional, isto é, a redução do constituído para o constituinte, dos fenômenos fundados para os fenômenos fundantes, esta é uma busca permanente. Devemos nos perguntar, portanto, se haveria em Husserl a busca de um ideal, a busca de uma única filosofia, a busca do conhecimento absoluto nunca abandonado.

Merleau-Ponty, por sua vez, aceita um tipo de redução transcendental, o segundo; ele também quer reduzir o constituído ao original. Mas a diferença em relação à Husserl é clara. O original está enterrado em uma "dimensão de obscuridade" e não pode ser trazido à luz. Contudo, em nosso diálogo com o mundo, atingimos o ponto onde o sentido mais original se dá, um sentido que é pré-consciente, pré-pessoal. Há uma espécie de diálogo misterioso, um enigma. Entretanto, Merleau-Ponty rejeita a possibilidade de uma iluminação absoluta do campo fenomenal, o que, dessa forma, o difere fundamentalmente de Husserl.

Em vista disto, se há um diálogo misterioso com o mundo, e a iluminação absoluta do campo fenomenal está descartada, se entendemos que "o mundo está ali antes de qualquer análise que eu possa fazer dele" (MERLEAU-PONTY, 1945, p. IV, 5), se "somos do começo ao fim relação ao mundo" (MERLEAU-PONTY, 1945, p. VIII, 10), devemos descartar a idéia de que o mundo é "um objeto do qual possuo comigo a lei de constituição" (MERLEAU-PONTY, 1945, p. V, 6), e o verdadeiro transcendental não é um "mundo transparente", mas a "vida ambígua."

Aqui, acreditamos, dá-se o movimento crucial na formulação do que é o verdadeiro transcendental e a vida reflexiva para Merleau-Ponty. É a partir tanto da valorização das descrições fenomenológicas, da necessidade de se crer nelas, e não vê-las como introduzindo um fator de irracionalidade e contradição na possibilidade do conhecimento, assim como pelo fato da filosofia estar "na história", e usar "o mundo e a razão constituída" (MERLEAUPONTY, 1945, p. XVI, 20), privando-se do recurso a postulados de apoio, os quais são usados nos outros conhecimentos - pois a filosofia é radical e desse modo é preciso que ela "dirija a si mesma a interrogação que dirige a todos os conhecimentos" (MERLEAU-PONTY, 1945, p. XVI, 20) -, que Merleau-Ponty define uma compreensão e uma reflexão mais radicais para justificar a necessidade de uma segunda redução, ou melhor, uma redução duplicada, mais radical do que a reflexão do pensamento objetivo para nelas integrar a vida irrefletida, o "fenômeno do real". Como ele diz ao final da segunda parte da Fenomenologia: "à fenomenologia entendida como descrição direta, deve acrescentar-se uma fenomenologia da fenomenologia" na busca de um "logos mais fundamental" (MERLEAU-PONTY, 1945, p. 
419, 489). A reflexão radical permanece sempre como uma descrição, mas agora como que redobrada.

Assim, precisamos não apenas instalar-nos em uma atitude reflexiva, mas ainda refletir sobre a reflexão, dar-nos conta da transformação que ela traz para o espetáculo do mundo e para nossa existência, fazendo aparecer um irrefletido sem absorvê-lo em uma consciência absoluta, mas deixando-o mostrar-se como uma mudança de estrutura de nossa existência. Além do mais, deve-se entender por irrefletido não aquilo que ainda não é refletido (porque inconsciente e disposto à nossa reflexão), mas um irrefletido que a reflexão faz aparecer como seu próprio suporte e ponto de apoio, como ponto de partida radical: o mundo ou nossa relação originária ao mundo. A redução é a única forma de reflexão que não absorve o irrefletido, mas que o mostra.

\subsubsection{A intencionalidade de ato e a intencionalidade operante}

Com a redução, portanto, Merleau-Ponty não pretende se retirar do mundo em direção a uma consciência pura. Se ele faz um recuo, se distende os fios intencionais que nos ligam ao mundo, é justamente para ver o mundo e tomar consciência de nossa relação com ele. Mas o que é a intencionalidade para Merleau-Ponty, e como ele a caracteriza face ao originário?

A intencionalidade de Merleau-Ponty não é a de Husserl. Grosso modo, sempre seguindo o preceito de que toda consciência é consciência de (algo), Husserl distingue, para Merleau-Ponty, dois tipos de intencionalidade: a intencionalidade de ato (do juizo, voluntária), e a intencionalidade operante (original, que aparece em nossa paisagem natural, ligada aos nossos desejos, antepredicativa) (MERLEAU-PONTY, 1945, p. XII, 16). Ele vai retomar a segunda ideia de intencionalidade husserliana, a intencionalidade desvinculada de seu caráter solipsista. Para ele, a intencionalidade operante identifica-se com toda atividade do sujeito que deixou de ser propriedade de uma consciência constituinte, isolada. Ela é abertura ao mundo de um sujeito corporal. É uma relação dialética, onde surge o sentido. Graças a ela, a essa "noção ampliada" da intencionalidade, a compreensão fenomenológica distingue-se da intelecção clássica que se limita às naturezas verdadeiras e imutáveis. "Quer se trate de uma coisa percebida, de um acontecimento histórico ou de uma doutrina, 'compreender' é reapoderar-se da intenção total” (MERLEAU-PONTY, 1945, p. XIII, 16). 
Todavia, quanto mais a reflexão é radical, menos esse mundo, paradoxalmente, se revela transparente; isto é, quanto mais a reflexão manifestar sua dependência em relação a uma vida "irrefletida", mais nos daremos conta de que a reflexão permanece incompleta na medida em que ela não tem consciência de seu próprio começo. Ela é problemática. Eis porque Merleau-Ponty fala, na esteira de Husserl, que "o maior ensinamento da redução é a impossibilidade de uma redução completa" ( $\mathrm{PhP}$, p. VIII, 10). O pensamento não pode abarcar todo nosso pensamento. "O filósofo, dizem ainda os inéditos [de Husserl, na época de Merleau-Ponty], é alguém que perpetuamente começa. [E a filosofia] é uma experiência renovada de seu próprio começo" (MERLEAU-PONTY, 1945, p. IX, 11).

\section{Fenômeno e descrição fenomenológica}

Um exemplo de descrição fenomenológica nos mostrará tanto a necessidade desse "perpétuo começo", quanto a ideia de que o "fenômeno" já aparece para nós, imediatamente, como um todo significativo. Isto é, meu campo fenomenal ou perceptivo, embora povoado de reflexos visuais, estalidos, de impressões táteis fugazes que não posso ligar de maneira precisa ao meu contexto perceptivo, situa-me imediatamente no mundo, sem confundi-lo com meras aparências ou minhas divagações. Com a redução, pela mediação do corpo, descortinamos não só o "campo transcendental" mas, também, e ao mesmo tempo, o "campo fenomenal", o qual não se caracteriza como uma realidade independente de nós. Nosso corpo, enquanto ser corporal doador de sentido, põe em evidência, através das estruturas fenomenais, uma realidade conectada à nossa existência, como prova de que - apesar de não possuirmos o mundo, pois ele é "inesgotável" -, nossa existência "pré-consciente", irrefletida, torna-se a “função primordial” pela qual fazemos o mundo existir para nós.

O exemplo é extraído do capítulo sobre a coisa e o mundo natural, da PhP. Para Merleau-Ponty, e também para Heidegger, mas de uma outra maneira, conforme Benedito Nunes (2004), a distinção entre "coisas e objetos" é fundamental. "Não sou apenas sujeito pensante (res cogitans) e o percebido não é apenas objeto" (2004, p. 3). O que une os termos numa "totalidade indefinida ou inacabada, é o mundo." "O que eu percebo é uma coisa, a que meu corpo se alia, e não o objeto da ciência física, em movimento no espaço tridimensional, e, como coisa, o percebido é presença corporal” (2004, p. 4). E, expressamente, diz MerleauPonty, “é por meu corpo que compreendo o outro, assim como é por meu corpo que percebo 
'coisas' ”'( MERLEAU-PONTY, 1945, p. 216, 253). Além disso, conforme Angela Ales Bello, em sua Introdução à Fenomenologia, a visão e o tato, sensações usadas por Merleau-Ponty em sua descrição, são "sensações fundamentais", “aquelas com as quais mais nos colocamos em contato com o mundo físico e conosco mesmos" (2006, p. 31). Examinemos, então, o exemplo de Merleau-Ponty.

A coisa visual ou a coisa tátil, e que se mantêm as mesmas em nossas experiências, não são nem um quale em sí, nem a consciência de uma propriedade objetiva. Os objetos se oferecem aos meus sentidos, ao olhar ou à palpação; minha mão conhece o granuloso e o liso, meu olhar conhece a luz, há aqui algo "como uma maneira de me unir ao fenômeno e de comunicar-me com ele [,] (...) uma certa maneira que o exterior tem de nos invadir, uma certa maneira que nós temos de acolhê-lo" (MERLEAU-PONTY, 1945, p. 425, 426). Tanto as propriedades sensoriais de uma coisa quanto meu olhar, meu tato, todos os meus outros sentidos são em conjunto as potências de um mesmo corpo integradas em uma só ação. "Percebo uma coisa porque tenho um campo de existência e porque cada fenômeno aparecido polariza em direção a si todo o meu corpo enquanto sistema de potência perceptivas". A experiência da coisa ou da realidade é a minha coexistência com o fenômeno, e este só se aproximará da existência real se falar a todos os meus sentidos, como por exemplo "o vento quando é violento e se faz visível na agitação da paisagem. Cézanne dizia que um quadro contém em sí até o odor da paisagem”. (MERLEAU-PONTY, 1945, p. 368, 427). Isto significa que uma coisa, para ter essa cor, precisa de todas as outras propriedades sensoriais. "Há na coisa uma simbólica que liga cada qualidade sensível às outras". (MERLEAUPONTY, 1945, p. 368, 428). Há uma significação presente na própria estrutura dos signos dos dados sensíveis. Pode-se dizer que "nossos sentidos interrogam as coisas e que elas lhes respondem". Retomamos por nossa conta o modo de existência dos signos observáveis das coisas em nossa volta. O sentido de uma coisa habita essa coisa "como a alma habita o corpo: ele não está atrás das aparências". Na percepção a coisa nos é dada "em pessoa" ou “em carne e osso". Ela é o "correlativo de meu corpo", de minha existência, e a descrição do real da experiência perceptiva está carregado de "predicados antropológicos". Se as relações entre as coisas são sempre mediadas por nosso corpo, então "a natureza inteira é a encenação de nossa própria vida ou nosso interlocutor em uma espécie de diálogo", e suas articulações são as mesmas de nossa existência. Na filosofia, se não se percebeu isso antes, foi porque os preconceitos (pre-juízos) do pensamento objetivo reduziu "todos os fenômenos que atestam a 
união do sujeito e do mundo", substituindo-os "pela idéia clara do objeto como em si e do sujeito como pura consciência". Na verdade, todas as coisas são "concreções de um ambiente", e em nossa comunicação com elas somos introduzidos em uma certa "atmosfera". Citando Scheler, Merleau-Ponty fala do objeto ausente:

o percebido não é necessariamente um objeto presente diante de mim como termo a
conhecer, ele pode ser uma 'unidade de valor' que só me está presente praticamente.
Se retiraram um quadro de um cômodo que habitamos, podemos perceber uma
mudança sem saber qual. É percebido tudo aquilo que faz parte de meu ambiente, e
meu ambiente compreende 'tudo aquilo cuja existência ou inexistência, cuja natureza
ou alteração contam para mim praticamente' (Scheler): a tempestade que ainda não
caiu (...) mas para a qual estou 'provido' e preparado; a periferia do campo visual que
o histérico não apreende expressamente, mas que todavia co-determina seus
movimentos e sua orientação; o respeito dos outros homens ou essa amizade fiel que
eu nem mesmo percebia mais, mas que estavam ali para mim, já que me deixam em
dificuldades quando se retiram (Scheler). (MERLEAU-PONTY, 1945, p. 371, 430).

Portanto, o fenômeno é compreendido como o termo que expressa as relações íntimas entre o objeto e o sujeito, ou melhor, entre a coisa ou o mundo humano e o sujeito-corporal. $\mathrm{O}$ real, diz Merleau-Ponty no prefácio da $\mathrm{PhP}$, deve ser descrito, não construído ou constituído. Se a realidade de minha percepção só estivesse fundada na coerência intrínseca das "representações", ela deveria ser sempre hesitante. "O real é um tecido sólido" $(\mathrm{PhP}, \mathrm{p} . \mathrm{V}, 6)$, e a presença de estruturas sólidas nos fenômenos os faz distintos de meras aparências.

Queremos terminar esta breve comunicação com uma citação de A Dúvida de Cézanne, de Merleau-Ponty:

Um pintor como Cézanne, um artista, um filósofo devem não apenas criar e exprimir uma idéia, mas ainda despertar as experiências que a enraizarão nas outras consciências (MERLEAU-PONTY, 1966, p. 33, 135).

\section{Referências}

ALES BELLO, Angela. Introdução à fenomenologia. Trad. Ir. Jacinta T. G e Miguel Mahfound. Bauru, SP: Edusc, 2006.

BORNHEIM, G. A. Introdução ao filosofar: o pensamento filosófico em bases existenciais. $5^{\text {a }}$ ed. Porto Alegre: Editora Globo, 1980.

CHAUÍ, M. de S. A experiência do pensamento: ensaios sobre as obras de Merleau-Ponty. São Paulo: Martins Fontes, 2002. 
DILLON, M. C. Merleau-Ponty's ontology. 2nd ed. Evanston: Northwestern University Press, 1997.

KWANT, R. C. Merleau-Ponty's criticism of Husserl's eidetic reduction. In: Phenomenology: the philosophy of E. Husserl and its interpretation. J. J. Kockelmans (ed.). New York: Anchor, 1967.

MERLEAU-PONTY, M. La structure du comportement. Paris: PUF,1967. td. J. A. Corrêa. A Estrutura do Comportamento. BH: Interlivros, 1975.

MERLEAU-PONTY, M. Phénoménologie de la perception. Paris: Gallimard, 1945. Trad. Carlos A.R. de Moura. Fenomenologia da Percepção. São Paulo: Martins Fontes, 1999.

MERLEAU-PONTY, M. Le doute de Cézanne. in: Sens et non-sens. Paris: Nagel, 1966. trad. Paulo Neves. A Dúvida de Cézanne. In: O olho e o espírito. São Paulo: Cosac \& Naify, 2004.

NUNES, Benedito. Physis, Natura - Heidegger and Merleau-Ponty. Nat. hum. [online]. Dec. 2004, vol.6, no.2 [cited 17 Jan 2007], p.271-287. Available from WorldWideWeb:

$<$ http://pepsic.bvspsi.org.br/scielo.php?script=sci_arttext\&pid=S1517-

$24302004000200004 \& \operatorname{lng}=e n \& n r m=i s o>$. ISSN 1517-2430.

SAINT AUBERT, Emmanuel De. Le scénario cartésien. Recherches sur la formation et la cohérence de l'intention philosophique de Merleau-Ponty. Paris: J. Vrin, 2005. 